\title{
Post-transcriptional restriction of gene expression in sea urchin interspecies hybrid embryos
}

\author{
Ronald A. Conlon, ${ }^{1}$ Frank Tufaro, ${ }^{2}$ and Bruce P. Brandhorst \\ Department of Biology, McGill University, Montreal, P.Q. H3A 1B1 Canada
}

The synthesis of many paternal species-specific proteins is reduced in all stages of sea urchin interspecies hybrid embryos, due to the reduced amounts of some paternal mRNA species in hybrid embryos compared with the embryos of the paternal species (Tufaro and Brandhorst 1982). Possible explanations for this restriction were tested. Cloned cDNAs were selected that were specific for paternal RNA sequences having reduced amounts (to 2-20\% of normal) in hybrid embryos derived from a cross of Strongylocentrotus purpuratus eggs with Lytechinus pictus sperm. Several of these RNA species are barely detectable in the eggs, but they accumulate extensively (5- to 40-fold) during $L$. pictus embryogenesis. Thus, the restricted expression of these paternal genes in hybrid embryos is not the result of the persistence of stable maternal mRNA species stored in eggs and not replaced by zygotic transcription. The accumulation of some of these $L$. pictus transcripts is also reduced in the reciprocal cross (L. pictus eggs $\times$ S. purpuratus sperm); therefore, the full expression of these $L$. pictus genes in hybrid embryos is not dependent on species-specific maternal factors stored in the egg. The transcriptional activity of one such gene was estimated using a run-on assay in isolated nuclei; it is as actively transcribed in hybrid as it is in homospecific embryos, but in hybrid embryos the cytoplasmic transcript accumulates to only $2-15 \%$ of the normal level. Sequence analysis indicates that this gene encodes a metallothionein. Mechanisms are discussed that might account for the post-transcriptional restriction of expression of some genes in hybrid embryos.

[Key Words: Metallothionein; post-transcriptional gene regulation; sea urchin embryo; mRNA stability; interspecies hybrids]

Received March 2, 1987; revised version received and accepted April 8, 1987.

The sea urchin has been studied extensively as a simple model of deuterostome embryonic development (for review, see Davidson 1986). Investigations of gene expression in echinoid embryos led to the development of the stored maternal mRNA hypothesis, historically an early indication of the importance of post-transcriptional gene regulatory mechanisms in eukaryotic cells. Most of the protein synthesis during the first few hours of embryogenesis of the sea urchin is directed by maternal mRNA stored in the egg and activated translationally upon fertilization (Gross et al. 1964; Humphreys 1971; Brandhorst 1985). Early embryogenesis proceeds normally until the hatching blastula stage, even in the absence of RNA synthesis (Gross et al. 1964). By the beginning of gastrulation most of the mRNA being translated is newly transcribed from the zygotic genome (Brandhorst and Humphreys 1972; Galau et al. 1977), and accumulation of new mRNA species first detectable at the blastula stage accounts for changes in protein synthesis that

\footnotetext{
'Present address: Zoology Department, University of Texas, Austin, Texas 78712 USA.

2Present address: Carnegie Institution, Department of Embryology, Baltimore, Maryland 21210 USA.
}

occur before gastrulation (Bédard and Brandhorst 1983, 1986). Analysis of the kinetics of accumulation of specific newly synthesized transcripts suggests that some maternal mRNAs are highly stable and persist throughout embryogenesis (Cabrera et al. 1982). Such stable mRNAs would provide a persistent maternal influence on embryonic development.

Long before the discovery of stored maternal mRNA, classic experiments on echinoid embryos had indicated that the maternal genome is largely responsible for directing the events of early embryogenesis. In particular, paternal characters were generally not detected in interspecies hybrid embryos or hybrid andromerogones until gastrulation (for review, see Davidson 1976; Chen and Baltzer 1979). The interpretation that the expression of the zygotic genome is not required during early embryonic development is dependent on the sensitivity of the assays used for patemal characters and on the assumption that paternal genes are properly expressed in hybrid embryos. In an effort to assess the relative roles of maternal and zygotic genomes in embryogenesis, the patterns of proteins synthesized by hybrid embryos were analyzed by two-dimensional gel electrophoresis (Tufaro 


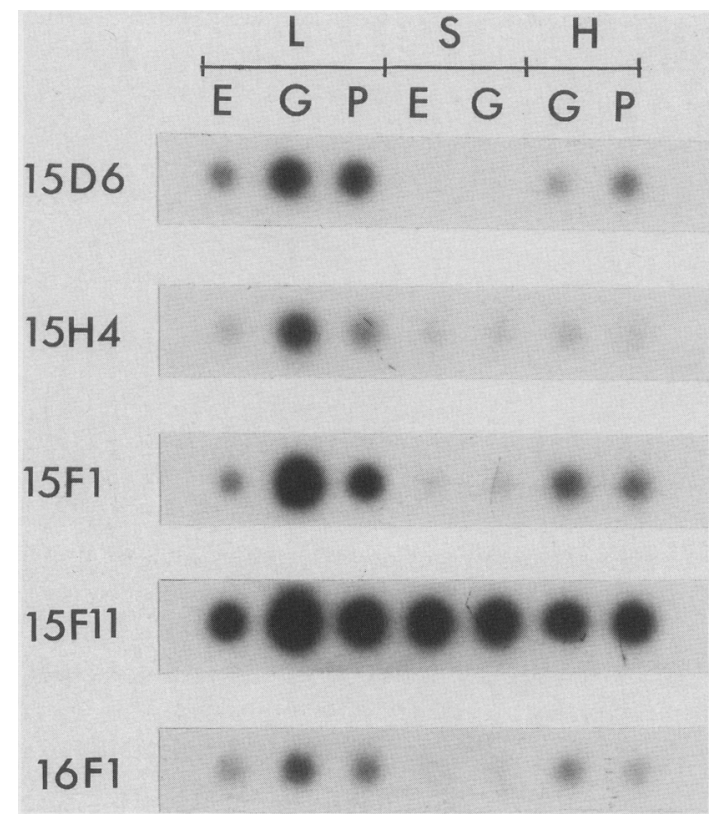

Figure 1. RNA dot-blot hybridization analysis of transcript prevalence in eggs and embryos. Cytoplasmic RNA was denatured, bound to GeneScreen filters, and hybridized with each of five recombinant plasmids labeled with ${ }^{32} \mathrm{P}$ by nick-translation (15D6, 15H4, 15F1, 15F11, 16F1). (L) L. pictus; (S) S. purpuratus; (H) S. purpuratus $(\mathrm{egg}) \times$ L. pictus hybrids; (E) egg; (G) gastrula; (P) pluteus. and Brandhorst 1982). Surprisingly, in three different crosses most paternal species-specific proteins were not synthesized detectably in hybrid embryos, even at the pluteus larva stage. For example, when Strongylocentrotus purpuratus eggs were fertilized with Lytechinus pictus sperm, of 130 distinctly paternal spots labeled with methionine, only two were observed to be labeled to comparable levels in hybrid plutei 3 days after fertilization. Analysis of cDNA hybridization kinetics indicated that this restriction is due to a reduced accumulation of some normally prevalent paternal mRNA sequences in hybrid embryos; there was no detectable loss of paternal DNA sequences encoding mRNA.

Two alternate explanations might account for these observations. The missing paternal mRNAs in hybrid embryos might normally be persistent maternal mRNAs not requiring replacement by the accumulation of $z y-$ gotic transcripts in embryos of the paternal species $(L$. pictus). If so, some of these persistent maternal transcripts would most likely be translationally regulated to account for the observed ontogenetic changes in the pattern of protein synthesis (Bédard and Brandhorst 1983). Alternatively, these mRNAs might accumulate in $L$. pictus embryos following fertilization, but their accumulation in hybrid embryos might be aberrant.

To distinguish between these alternate explanations, we have selected cDNAs for use in analyzing the expression of several $L$. pictus genes in hybrid embryos. Several

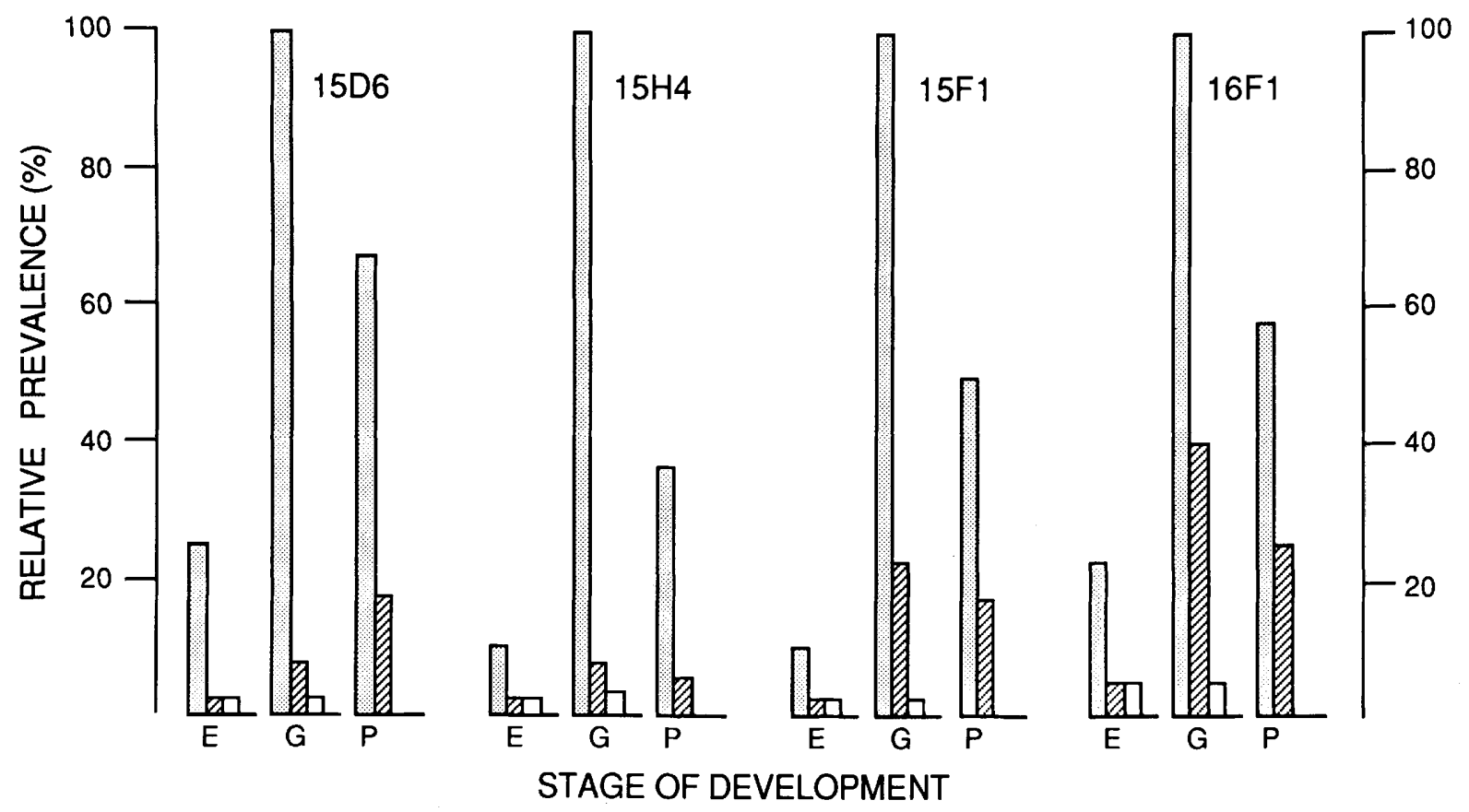

Figure 2. Transcript prevalence in L. pictus and $S$. purpuratus eggs and embryos, and $S$. purpuratus (egg) $\times \dot{L}$. pictus hybrid embryos. Quantitation by densitometry of RNA dot blots as shown in Fig. 1 is provided. Prevalence is expressed as a percentage of the maximum integrated optical density value for each transcript. The values for "hybrid" eggs are those for $S$. purpuratus eggs; no determination was made for $S$. purpuratus plutei. (E) egg; (G) gastrula; (P) pluteus. (Stippled bars) L. pictus; (cross-hatched bars) S. purpuratus $\times$ L. pictus; (open bars) $S$. purpuratus. 
mRNAs accumulate extensively in $L$. pictus embryos, but not in reciprocal hybrid embryos. The transcriptional activity of one of these genes is the same in $L$. pictus and hybrid embryos, indicating a post-transcriptionally mediated restriction on its expression in hybrid embryos.

\section{Results \\ Restricted accumulation of L. pictus transcripts in hybrid embryos}

If persistence of maternal mRNA is the general explanation for the restricted expression of $L$. pictus genes in $S$. purpuratus (egg) $\times$ L. pictus embryos, then it follows that a set of $L$. pictus species-specific mRNA sequences represented at reduced levels in hybrid gastrulae or plutei should show little or no accumulation during $L$. pictus embryogenesis following fertilization. To test this prediction, we took advantage of the large divergence in nucleotide sequence between these two sea urchin species, which separated about 100 million years ago and are commonly classified in different echinoid orders (Angerer et al. 1976).

A cDNA library was constructed from $L$. pictus gastrula-stage polyadenylated cytoplasmic RNA primed for reverse transcription by oligo(dT). This library was screened by colony hybridization for cDNA clones corresponding to relatively prevalent polyadenylated cytoplasmic transcripts. Plasmids were prepared from these colonies, spotted onto GeneScreen filters, and hybridized to radioactive cDNA transcribed from polyadenylated cytoplasmic RNA prepared from L. pictus or S. purpuratus eggs, gastrulae, and plutei, as well as from $S$. purpuratus (egg) $\times$ L. pictus hybrid gastrulae or plutei. Of 40 species-specific cDNA clones identified and analyzed, 27 corresponded to transcripts having considerably reduced prevalence in hybrid gastrulae compared with $L$. pictus gastrulae. Most showed substantial increases in prevalence between egg and gastrula or pluteus stages, many being undetectable or barely detectable in eggs. Thus, the persistence of maternal mRNA in $L$. pictus embryos cannot be a general explanation for the restricted expression of $L$. pictus mRNA sequences in hybrid embryos. The mechanisms responsible for the normal accumulation of these transcripts in L. pictus embryos must be perturbed in hybrid embryos.

The behavior of transcripts corresponding to four such cDNA clones is presented here. While some species-specific prevalent transcripts hybridized to mitochondrial DNA, these four did not. Cytoplasmic RNA was spotted onto duplicate GeneScreen filters and hybridized to each of five nick-translated recombinant plasmids as shown in Figure 1. The plasmid 15F1 corresponds to a prevalent transcript detected in eggs and embryos of both species. Densitometric quantitation of the accumulation of transcripts corresponding to $15 \mathrm{D} 6,15 \mathrm{H} 4,15 \mathrm{~F} 1$, and $16 \mathrm{~F} 1$ is shown in Figure 2; in all four instances, the RNA sequence increased in prevalence during embryogenesis $(5-40 \times)$ and showed restricted accumulation in hybrid gastrulae and plutei (reduced to $4-20 \%$ of normal).

The representation of transcripts corresponding to these four cDNAs in total cellular RNA of normal and hybrid embryos is shown in the RNA gel blot analyses shown in Figure 3. In lanes 1-3, the accumulation of the

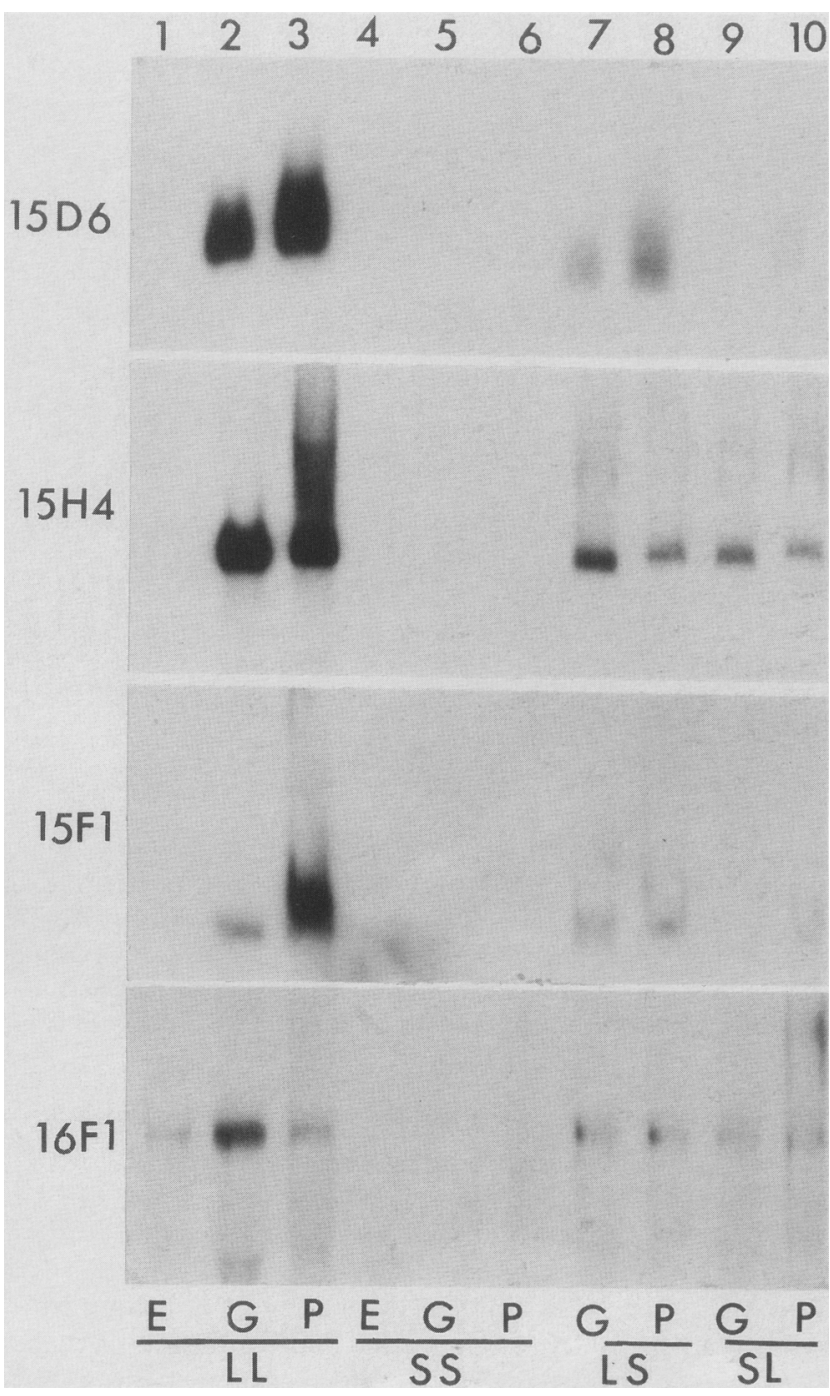

Figure 3. RNA gel-blot analysis of transcript prevalence in eggs and embryos. Total RNA was prepared from eggs and embryos, denatured and separated on $2 \%$ agarose gels by electrophoresis, blotted onto GeneScreen, and hybridized to cloned cDNAs. The inserts of 15D6 and 15F1 had been subcloned into Bluescribe; the 15D6 subclone lacked coding sequence and shows greater species-specificity than 15D6 DNA. The Bluescribe subclones were transcribed into single-stranded RNA labeled with ${ }^{32} \mathrm{P}$; posthybridization washes were carried out at $72^{\circ} \mathrm{C}$. The plasmids $15 \mathrm{H} 4$ and $16 \mathrm{~F} 1$ were nick-translated and denatured prior to hybridization. (Lanes $1-3$ ) L. pictus (LL), (lanes 4-6) S. purpuratus (SS); (lanes 7-8) L. pictus eggs $\times S$. purpuratus sperm (LS); (lanes 9-10) S. purpuratus eggs $\times L$. pictus sperm (SL). Lanes 1 and 4 contain egg RNA (E); lanes 2, 5 , 7 , and 9 contain gastrula RNA (G); lanes $3,6,8$, and 10 contain pluteus RNA $(\mathrm{P})$. 


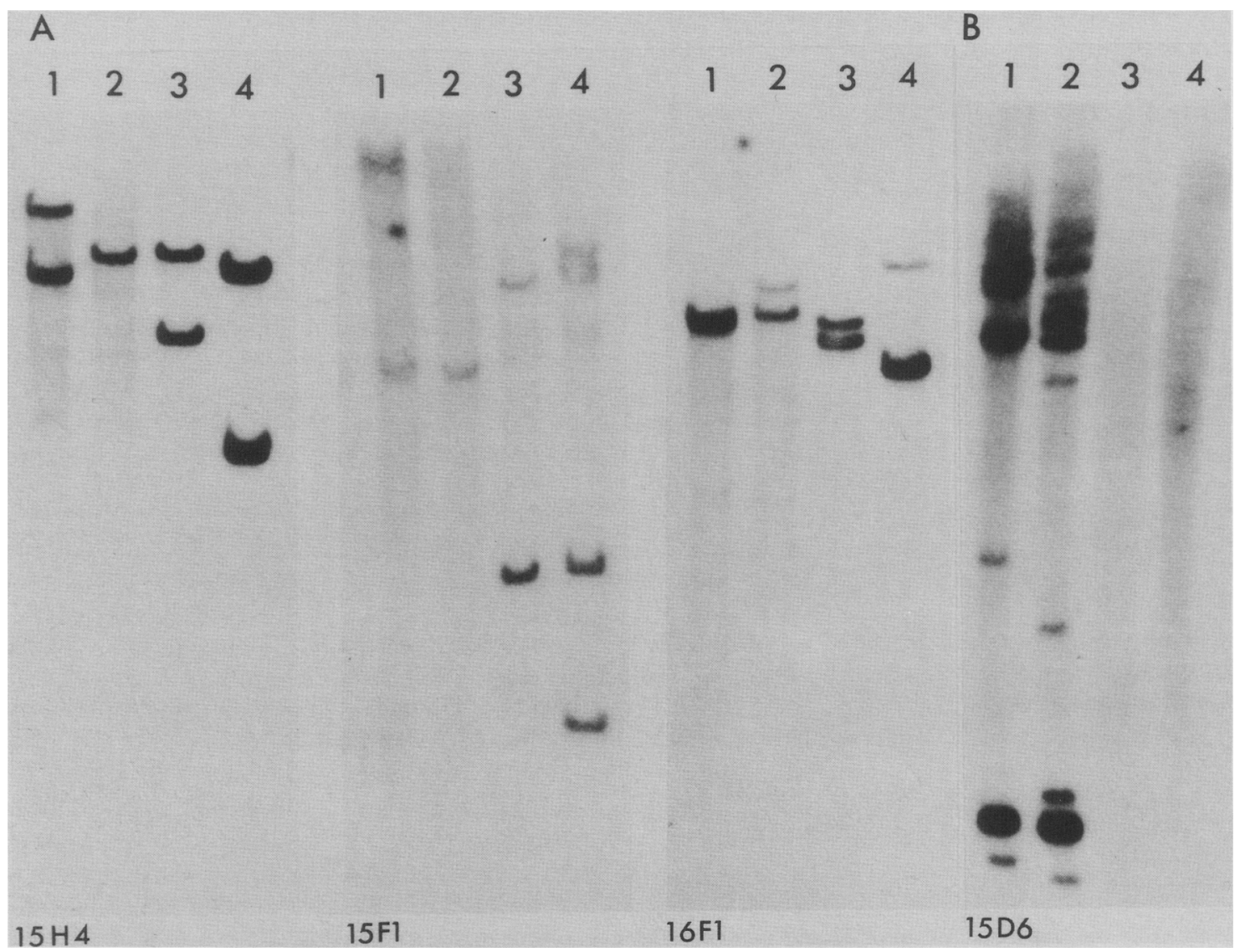

Figure 4. Southern blot analysis genes corresponding to four cloned cDNAs. Genomic DNA was prepared from sperm of two different $L$. pictus or S. purpuratus donor animals, restriction digested, size-fractionated by electrophoresis, blotted onto GeneScreen Plus membranes, and hybridized with nick-translated cDNA inserts corresponding to 15H4, 15F1, and 16F1. (A) (Lanes 1 and 2) PstI digestion; (lanes 3 and 4) EcoRI digestion; (lanes 1 and 3) donor $A_{;}$(lanes 2 and 4) donor B. (B) (Lanes 1 and 2) $10 \mu g$ L. pictus genomic DNA from donors A and B, respectively, digested with PstI; (lanes 3 and 4) $20 \mu \mathrm{g}$ S. purpuratus genomic DNA from donors A and B, digested with PstI. This blot was hybridized with nick-translated 15D6 insert DNA.

transcripts during embryogenesis of $L$. pictus is shown. The failure to detect these transcripts in $S$. purpuratus eggs and embryos is shown in lanes 4-6. The reduced accumulation of these transcripts in $S$. purpuratus (egg) $\times L$. pictus hybrid embryos is shown in lanes $9-10$. These results and those of Figures 1 and 2 are consistent with the hypothesis that the expression of these L. pictus genes requires the presence of factors not present in the cytoplasm of $S$. purpuratus eggs. That this is not so is indicated by the similarly reduced accumulation of these four transcripts in the reciprocal hybrids, $L$. pictus (egg) $\times$ S. purpuratus (Fig. 3, lanes 7 and 8 ); such hybrid embryos should include any maternally derived factors required for the expression of these $L$. pictus genes. Thus, the presence of the $S$. purpuratus genome or genes precludes the normal expression of several $L$. pictus genes in hybrid embryos.

These four cDNA clones do not cross-hybridize and they show distinctive patterns of hybridization to blots of cellular RNA. In all instances a single major transcript was observed (Fig. 3), and is concentrated in the cytoplasm (data not shown). After long exposures, larger transcripts can be detected and probably correspond to nuclear precursors; they are more evident when blotted from gels having lower concentrations of agarose. Further evidence that these cDNAs correspond to distinct and unrelated genes is shown in the genomic blot hybridizations of Figure 4 . The cDNAs $15 \mathrm{H} 4,15 \mathrm{~F} 1$, and 16Fl (Fig. 4A) show simple but distinctive patterns of hybridization characteristic of single-copy genes in a genome having substantial nucleotide sequence polymorphism (Grula et al. 1982; Posakony et al. 1983). As shown in Figure 4B, the cDNA clone 15D6 hybridizes to a more complex array of restriction fragments of the $L$. pictus genome, but does not hybridize detectably to $S$. purpuratus DNA under these conditions. DNA dot blot reconstructions indicate that in $L$. pictus there are 5-10 copies of sequences related to 15D6 per haploid genome.

Transcriptional activity of 15D6 genes is unaltered in hybrid embryos

The failure of some $L$. pictus transcripts to accumulate to normal amounts in the presence of the $S$. purpuratus genome might be the result of unsuccessful competition by the $L$. pictus genes for limiting transcription factors. To test this hypothesis, the relative rates of transcrip- 


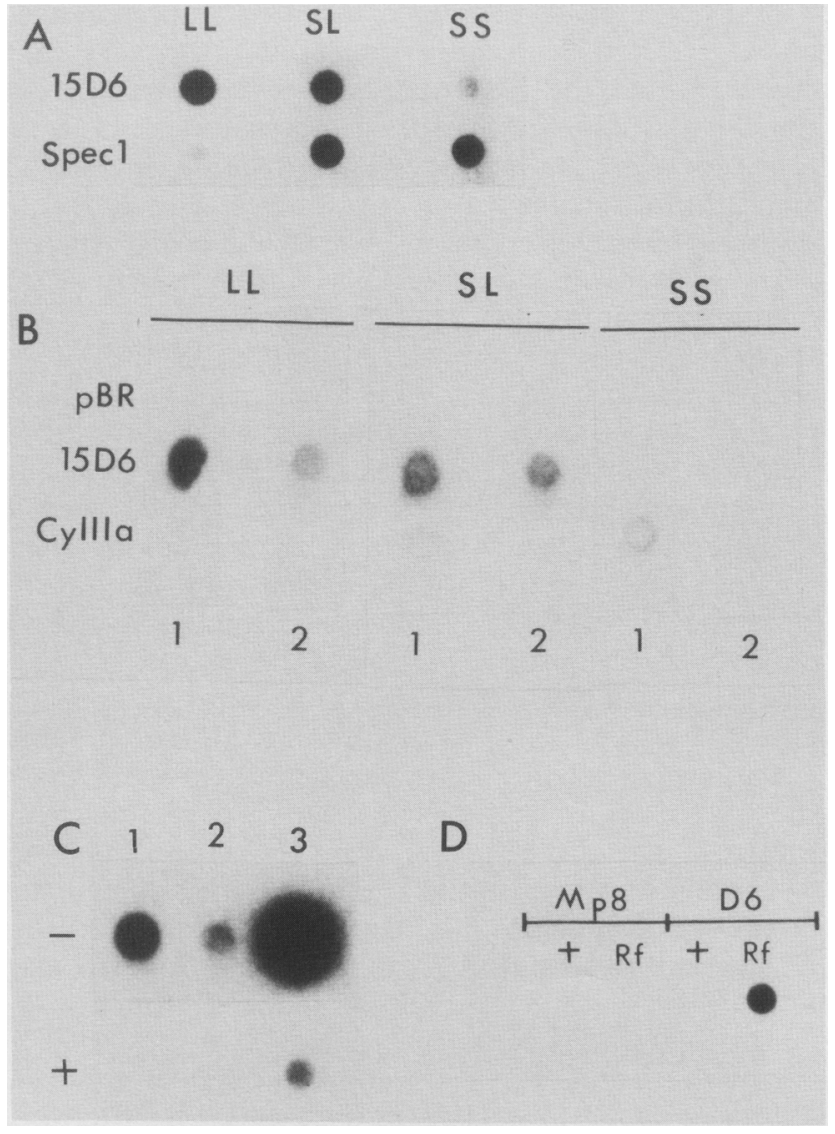

tion of 15D6 genes were estimated. Nuclei were prepared from $L$. pictus and $S$. purpuratus $(\mathrm{egg}) \times L$. pictus hybrid mesenchyme blastulae, a stage when the 15D6 transcript is rapidly accumulating in L. pictus embryos. RNA was labeled by run-on synthesis in these nuclei. As shown in Figure 5, there is little difference in the fraction of labeled RNA from $L$. pictus and hybrid nuclei that hybridizes to 15D6 DNA. This type of investigation has been carried out many times at a variety of stages. No reduction in the relative transcriptional activity of the 15D6 gene(s) in hybrid embryos was ever observed; in fact, we usually observed a transcriptional compensation for the reduced dosage of the 15D6 gene(s) in hybrid embryos.

To assess the validity of the run-on assay, the expression of several other genes was also analyzed. Figure 5A shows the transcription of Spec1, an S. purpuratus gene encoding a calcium-binding protein (Carpenter et al. 1984), which is actively transcribed in S. purpuratus and hybrid embryos, but not detectably expressed in $L$. pictus embryos (and not detectable in the L. pictus genome). Figure 5B shows the hybridization of run-on labeled RNA to DNA corresponding to the $3^{\prime}$ end of the S. purpuratus actin gene CyIIIa (Lee et al. 1986); this species-specific DNA sequence is actively transcribed in $S$. purpuratus and hybrid embryos. The extension of 15D6 RNA chains in isolated nuclei is greatly reduced by treatment with a low concentration of $a$-amanitin, indicating that the gene is transcribed by polymerase II
Figure 5. RNA run-on analysis of transcriptional activity of 15D6 genes in hybrid embryos. Nuclei were isolated from embryos and incubated with [ ${ }^{32}$ P]UTP under conditions allowing RNA chain extension. The RNA was purified and hybridized to filter-bound plasmid DNA. Equal inputs of radioactivity were used for samples compared. (A) RNA prepared from $S$. purpuratus (SS), L. pictus (LL), or S. purpuratus (eggs) $\times$ L. pictus hybrid (SL) embryos (mesenchyme blastulae) was hybridized to 15 D6 or Specl plasmid DNA. $(B)$ A different experiment in which RNA prepared from a similar set of crosses was hybridized to pBR322 (pBR), 15D6, and CyIIIa actin plasmid DNA. Inputs for lane $1,1 \times 10^{6} \mathrm{cpm}$; for lane $2,0.5 \times 10^{6} \mathrm{cpm}$. $(\mathrm{C})$ Chain extension in isolated nuclei occurred in the absence $(-)$ or presence $(+)$ of $1 \mu \mathrm{g} / \mathrm{ml} \alpha$-amanitin, and RNA was hybridized to 15D6 (lane 1); pBR322 (lane 2); and 16B7 (lane 3) (which includes a very actively transcribed repetitive sequence element). Densitometry indicated that transcription of $15 \mathrm{D} 6 \mathrm{se}-$ quences was reduced to $1 \%$ in the presence of the inhibitor. $(D)$ Demonstration of asymmetry of transcription of 15D6 DNA sequences. A subclone of 15D6 DNA was prepared in the Mp8 derivative of $\mathrm{M} 13$ phage. The (+) strand, corresponding to the 15D6 mRNA sequence, was prepared, as well as the replicative form (Rf), which includes the $(-)$ strand; these were bound to a nitrocellulose membrane in a mass ratio of $1: 2$ for $1+1 / R f$ DNA. RNA labeled by chain extension in nuclei isolated from hybrid embryos was hybridized to filter-bound DNA. Also shown is the hybridization of the RNA to Mp8 DNA lacking an insert.

(Fig. 5C). As demonstrated in Figure 5D, only one strand of 15D6 DNA is detectably labeled by chain extension in nuclei of hybrid embryos. A similar analysis indicated that the same strand is transcribed exclusively in isolated nuclei of $L$. pictus embryos and accounts for all of the hybridization of kinase-labeled cytoplasmic RNA of L. pictus embryos to 15D6 RNA (data not shown). Southern blot (see Fig. 4) and DNA dot blot analyses indicated that 15D6 DNA includes few, if any, repetitive sequence elements. Thus, the run-on assay detects the transcription of the 15D6 gene or one of its few homologs; unless there is differential reinitiation, elongation, or premature termination in nuclei isolated from $L$. pictus or hybrid embryos, the run-on assay provides an estimate of the fraction of polymerase II molecules engaged in the transcription of 15D6 DNA. On the basis of these observations, we conclude that the rate of synthesis of 15D6 RNA is similar in hybrid and L. pictus embryos, indicating that the expression of the 15D6 gene(s) is post-transcriptionally restricted in these hybrid embryos. A similar run-on assay indicated that the transcriptional activity of 15D6 DNA is indistinguishable in $L$. pictus embryos and hybrid embryos of the $L$. pictus (egg) $\times S$. purpuratus cross (data not shown).

The fraction of run-on labeled RNA hybridizing to 15D6 DNA varied among experiments but was normally about $10^{-4}$; this high transcriptional activity of a gene or small gene family is unusual in sea urchin embryos $(R$. Conlon 1985/ and facilitates this type of analysis. The 
fraction of $L$. pictus run-on labeled RNA which hybridized to $15 \mathrm{H} 4,15 \mathrm{~F} 1$, and $16 \mathrm{~F} 1$ was considerably less, being only slightly above the background hybridization to pBR322 plasmid DNA. Thus, no firm conclusions can be drawn presently concerning the level of restriction of expression of these three genes.

\section{The 15D6 mRNA encodes metallothionein}

The insert of clone 15D6 was sequenced and an open reading frame identified encoding a cysteine-rich polypeptide. A homolog of 15D6 having a larger insert, 15C9, was also sequenced. As shown in Figure 6, the open reading frames of 15D6 and 15C9 encode polypeptides having deduced amino acid sequences showing a high degree of homology with $S$. purpuratus metallothioneins MTa and MTb (Nemer et al. 1985; Wilkinson and Nemer 1987); in particular, the positions of the cysteine residues are conserved. Treatment of $L$. pictus embryos with zinc ions resulted in an increased concentration of 15D6 transcripts, as anticipated for mRNA encoding metallothionein (Nemer et al. 1984).

\section{Discussion}

The results of the run-on transcription assay indicate that the rate of synthesis of 15D6 RNA is similar in $L$. pictus and hybrid embryos. This implies that the restriction on accumulation of this transcript is mediated posttranscriptionally. Because 15D6 is a member of a small gene family, the unlikely possibility remains that the gene transcribed to give rise to the 15D6 cytoplasmic transcript is restricted in transcriptional activity in hybrid embryos, while other 15D6 genes are transcribed actively in both hybrid and L. pictus embryos, but do not give rise to significant amounts of cytoplasmic transcripts. A post-transcriptional restriction on RNA accumulation could operate either at the level of nuclear processing, stabilization, and transport of the mRNA, or at the level of cytoplasmic mRNA stability. RNA blot analyses of total RNA do not indicate an aberrant appearance or accumulation of putative nuclear precursors in hybrids, but a rapid turnover of nuclear precursors is possible. The $15 \mathrm{D} 6$ transcripts that accumulate in the hybrid cytoplasm are indistinguishable in size from those observed in L. pictus embryos and are polyadenylated (data not shown). The stability of 15D6 mRNA in hybrid embryos is being analyzed.
A possible mechanism for a post-transcriptionally mediated restriction in transcript accumulation is that some $L$. pictus mRNAs may have reduced stability in the cytoplasm of $S$. purpuratus embryos; for instance, a species-specific trans-acting factor required for mRNA stabilization might be stored in the egg. This model is excluded by the observations presented in Figure 3 (lanes 7 and 8 ), because such factors would be present in $L$. pictus eggs.

The observation that the accumulation of four $L$. pictus transcripts in the cytoplasm is reduced in reciprocal hybrid embryos suggests that the presence of the $S$. purpuratus genome, or information derived from it, has a dominant repressive effect on the expression of several L. pictus genes. Two-dimensional electrophoretic analyses of protein synthesis indicate that some distinctive $L$. pictus proteins are synthesized normally in hybrid embryos derived from $L$. pictus eggs; there is no generalized repression of the expression of $L$. pictus genes in the presence of the $S$. purpuratus genome. Moreover, some $S$. purpuratus (paternal) proteins are not detectably synthesized in these hybrids. The majority of proteins synthesized by embryos of the two species comigrate on two-dimensional separations; no conclusions about the origin of mRNAs encoding these proteins can be drawn. $L$. pictus histone mRNA can be detected before the first cleavage in hybrid embryos produced from $S$. purpuratus eggs (Maxson and Egrie 1980). At least two $S$. purpuratus actin mRNAs accumulate appropriately in hybrid embryos formed in crosses with $L$. variegatus (Crain and Bushman 1983). Some species-specific isozymes show normal patterns of expression in hybrid embryos (e.g., Fedecka-Bruner et al. 1971) while others do not (e.g., Ozaki 1975). Nucleic acid hybridization analyses suggest that many rare paternal transcripts are represented in hybrid embryos, while more prevalent mRNAs are frequently reduced (Tufaro and Brandhorst 1982). A general explanation for the restricted expression of these $L$. pictus genes in hybrid embryos therefore must account for both the normal expression of some genes and the reduced mRNA levels of many others.

A nucleolar dominance effect is observed in a wide variety of interspecies hybrid crosses for various plant and animal species. For instance, the transcription of Xenopus borealis ribosomal DNA is repressed in the presence of $X$. laevis ribosomal DNA in hybrid embryos
10

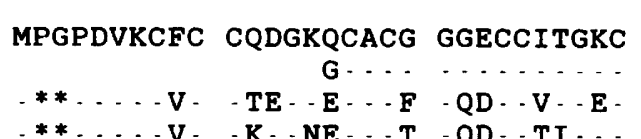

30

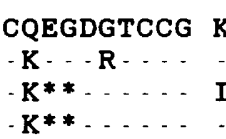

50

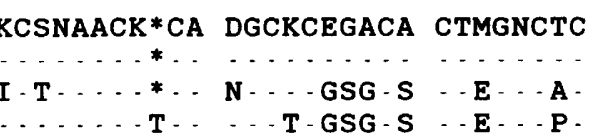

Figure 6. Deduced amino acid sequences of $15 \mathrm{D} 6$ and $15 \mathrm{C} 9$. Inserts of the L. pictus $15 \mathrm{D} 6 \mathrm{cDNA}$ clone and its homolog $15 \mathrm{C} 9$ were sequenced, and the deduced amino acid sequences of the open reading frames are shown. For comparison the deduced amino acid sequences of the S. purpuratus metallothioneins MTa and MTb are shown (Wilkinson and Nemer 1987). Amino acid identities and numbering are shown for the $15 \mathrm{C} 9$ sequence. Amino acids shared with $15 \mathrm{C} 9$ are shown by dashes; divergent amino acids are shown. Gaps, indicated by asterisks, were introduced to maximize sequence homologies; blank spaces indicate the lack of sequence information. 
(Honjo and Reeder 1973; Reeder 1985); this appears to be due to an imbalance in the transcriptional enhancer elements associated with the ribosomal genes of the two species. In other instances, nucleolar dominance appears to be the result of species-specific transcription factors (Reeder 1985). Polymerase I gene systems probably evolve more rapidly than polymerase II systems, which are constrained by the large number of different transcription units that must be expressed (Reeder 1985). In the case of 15D6 gene expression in echinoid hybrids, the evidence that (at least in one instance) post-transcriptional events are responsible for our observations is not consistent with either of the proposed mechanisms of nucleolar dominance; it is possible that trans-acting factors interacting with transcripts (e.g., to control stability) might be involved, though the coevolution of factors showing sequence preferences for a large subset of transcripts of a particular species is difficult to envision.

Evidence has accumulated that the maternal and paternal genomes remain distinct during early mammalian embryogenesis; for example, the male $\mathrm{X}$ chromosome is inactivated selectively in extraembryonic endodermal cells of mice, indicating that it retains distinctive features after pronuclear fusion (Tagaki and Sasaki 1975), and both the maternal and paternal pronuclei are required for normal development (McGrath and Solter 1984; Surani et al. 1986). The evidence for post-transcriptional events and species dominance effects in echinoid hybrid embryos indicates that differential activities of the paternal and maternal genomes during embryogenesis cannot be a general explanation for our observations. Moreover, in sea urchins either parental genome is sufficient for development to adult (reviewed by Hörstadius 1939|.

The restricted expression of some genes in hybrid embryos might be due to a competition between gene or transcript homologs for factors required for active expression. In the case of 15D6 (metallothionein) mRNA, these factors might be required for efficient transcript stabilization or processing in the nucleus or stabilization of the mRNA in the cytoplasm. It is possible that the overall rate of metallothionein production is similar in hybrid and homospecific embryos of the same stage, but that the $\mathrm{Sp}$ transcript homolog competes more effectively for limiting factors required for its efficient accumulation. The restricted accumulation of 15D6 mRNA might then be a reflection of an autogenous regulation of metallothionein synthesis normally mediated post-transcriptionally in echinoid embryos, perhaps in response to concentrations of heavy metals (Nemer et al. 1984). Metallothionein gene expression is autogenously regulated in yeast via heavy metals, though evidently at the level of transcription (Hamer et al. 1985; Thiele et al. 1986). We have proposed that post-transcriptionally mediated autogenous regulation of protein synthesis might occur via cotranslational competition of nascent proteins for factors resulting in mRNA stabilization (Brandhorst et al. 1986). We are currently testing some predictions derived from this model.

Our investigations indicate that a critical assumption involved in a classic experimental approach to echinoid embryology, the use of interspecies hybrids, is not always valid: The expression of paternal genes is sometimes aberrant. Nevertheless, the general conclusions concerning the preponderant role of the maternal genome in early embryonic development have become well established (Davidson 1986). An understanding of the basis for restricted expression of genes in hybrid embryos is likely to provide important information concerning the mechanisms and role of selective gene regulation during embryogenesis. Moreover, clarification of aberrations in gene regulation in hybrids formed between related species may prove instructive in consideration of the mechanisms responsible for speciation.

\section{Materials and methods}

\section{Fertilization and culturing of embryos}

Unless otherwise noted, embryo cultures were prepared as described by Klein et al. (1986). For the preparation of hybrid embryos, solid trypsin (Sigma, type IIIS) was added at $0.25 \mathrm{mg} / \mathrm{ml}$ to a suspension of $L$. pictus eggs in artificial seawater (ASW) in a centrifuge tube; after $5 \mathrm{~min}$ the eggs were collected and washed two or three times through ASW by light centrifugation. They were resuspended and inseminated with a $1: 200$ dilution of $S$. purpuratus sperm. The yield of hybrid zygotes ranged from 10 to $90 \%$, averaging about $40 \%$ after expansion of the blastocoel; hybrid embryos were separated from unfertilized eggs by passage through $44-\mu \mathrm{m}$ nylon mesh (Nitex). S. purpuratus eggs to be fertilized by $L$. pictus sperm were prepared and inseminated in the same way except that trypsin treatment was $1 \mathrm{~min}$; in some instances, these hybrids were prepared as described previously (Tufaro and Brandhorst 1982). Embryos were cultured at $15^{\circ} \mathrm{C}$. Nearly all the hybrid embryos hatched and formed healthy plutei capable of feeding; hybrids formed by treatment of $S$. purpuratus eggs with trypsin sometimes arrested at the prism stage.

\section{Preparation of RNA and DNA}

For preparations of cytoplasmic RNA, embryos were collected by gentle centrifugation and washed successively through cold calcium-magnesium-free ASW (CMFSW) and polysome buffer $10.4 \mathrm{~N} \mathrm{NH}_{4} \mathrm{Cl}, 0.05 \mathrm{M} \mathrm{MgCl}_{2}, 0.025 \mathrm{M}$ EGTA, and $0.05 \mathrm{M}$ PIPES, $\mathrm{pH}$ 6.8). The washed embryos were resuspended in 5 volumes of cold polysome buffer containing $0.5 \%(\mathrm{wt} / \mathrm{vol})$ Triton X-100 and homogenized with five strokes of the tight pestle of a Dounce homogenizer. Nuclei were removed by centrifugation at $12,000 \mathrm{~g}$ for $10 \mathrm{~min}$. To the supernatant was added an equal volume of $4 \mathrm{M} \mathrm{LiCl}, 8 \mathrm{M}$ urea, $0.5 \mathrm{~mm}$ EDTA, $20 \mathrm{~mm}$ Tris- $\mathrm{HCl}$ (pH 7.5), and the RNA was precipitated overnight at $-20^{\circ} \mathrm{C}$. The RNA was collected by centrifugation at $20,000 \mathrm{~g}$ for $20 \mathrm{~min}$ and resuspended in $0.1 \mathrm{M}$ sodium acetate $(\mathrm{pH} 5.0), 25 \mathrm{~mm}$ EGTA, $0.5 \%$ SDS, and extracted several times with phenol/ chloroform/isoamyl alcohol (50: $48: 2)$. RNA was precipitated from the aqueous phase by addition of 2.5 volumes of ethanol. For the preparation of cytoplasmic RNA used for reverse transcription, embryos were homogenized in the absence of Triton $\mathrm{X}-100$ to minimize the amount of mitochondrial RNA. Polyadenylated RNA was selected by affinity chromatography on oligo(dT)-cellulose (Brandhorst et al. 1979).

Total RNA was prepared as described by March et al. (1985). Briefly, embryos were washed with CMFSW and homogenized in 5-10 volumes of guanidine isothiocyanate solution. RNA 
was precipitated with ethanol, redissolved and differentially precipitated from guanidine hydrochloride, redissolved and extracted with phenol/chloroform, and precipitated with ethanol.

Genomic DNA was prepared from sperm essentially as described by Blin and Stafford (1976).

\section{Construction of a cDNA library}

Unless noted otherwise, recombinant DNA methods were essentially as described by Maniatis et al. (1982). Polyadenylated cytoplasmic RNA prepared from early $L$. pictus gastrulae (22-hr embryos raised at $17^{\circ} \mathrm{C}$ was primed with oligo(dT) for preparation of double-stranded cDNA. The cDNA was tailed with dCMP and annealed to pBR322 restricted with PstI and dGMP. tailed. The recombinant plasmids were used to transform $E$. coli strain $\mathrm{DH} 1$; approximately 1300 tetracycline-resistant, ampicillin-sensitive colonies were selected. The inserts of recombinant plasmids isolated from this library were a few hundred base pairs long on average; thus, they are frequently useful as $3^{\prime}$ end-specific probes for mRNAs that may share coding sequence homology. The cDNA nomenclature is based on microtiter plate number and position. Those cited in this report had been replated onto plates 15 and 16 , and are formally identified by the prefix ftpLpG. In some instances restriction fragments of these clones have been subcloned into the $\mathrm{Mp} 7$ and 8 derivatives of $\mathrm{M} 13$ phage or into Bluescribe (Stratagene Cloning Systems| vectors.

\section{Filter hybridization assays}

Plasmid DNA was partially depurinated, denatured by incubation with $\mathrm{NaOH}$, neutralized, and $10 \mu \mathrm{g}$ samples spotted onto GeneScreen (New England Nuclear) or nitrocellulose filters using a BRL manifold. RNA was denatured in $12 \mu \mathrm{l}$ of $20 \mathrm{~mm}$ MOPS, $50 \%$ formamide, $6.6 \%$ formaldehyde at $65^{\circ} \mathrm{C}$ for $5 \mathrm{~min}$ diluted with $0.1 \mathrm{ml} 1 \times \mathrm{SET} / 0.15 \mathrm{M} \mathrm{NaCl}, 2 \mathrm{mM}$ EDTA, $30 \mathrm{~mm}$ Tris- $\mathrm{HCl}, \mathrm{pH} 8.0$ ), quickly cooled, and spotted onto GeneScreen. Genomic DNA was digested with EcoRI or PstI, separated by electrophoresis through agarose, and blotted onto GeneScreen Plus filters using the manufacturer's recommended protocol. Denatured RNA was separated by electrophoresis through agarose gels containing formaldehyde according to Lehrach et al. (1977), and was blotted onto GeneScreen filters. The filters were baked for $2-4 \mathrm{hr}$ at $80-90^{\circ} \mathrm{C}$ or irradiated with UV light according to Church and Gilbert (1984). Plasmid DNA was labeled with ${ }^{32} \mathrm{P}$ by nick-translation and labeled cDNA was synthesized by reverse transcription of oligo(dT)-primed polyadenylated cytoplasmic RNA. Single-stranded RNA probes of high specific activity were produced from subclones in Bluescribe vectors according to instructions of the manufacturer.

Hybridization solution for GeneScreen filters consisted of $50 \%$ formamide, $4 \times$ SET, $1 \times$ Denhardt's solution, $0.2 \%$ sodium pyrophosphate, $100 \mu \mathrm{g} / \mathrm{ml}$ denatured, sheared salmon sperm DNA, $100 \mu \mathrm{g} / \mathrm{ml}$ poly(A), $10 \%$ dextran sulfate, and $1 \%$ SDS. For GeneScreen Plus filters, the salmon sperm DNA and pyrophosphate were omitted. Filters were prehybridized for at least $6 \mathrm{hr}$, radioactive probe was added, and hybridization carried out at $42^{\circ} \mathrm{C}$ in sealed bags. Complex probes (e.g., chain-extended RNA) were hybridized for at least $48 \mathrm{hr}$, while less complex probes were hybridized overnight. The filters were then washed with $2 \times$ SET, $0.1 \%$ SDS, $0.1 \%$ sodium pyrophosphate at room temperature, and then at $65^{\circ} \mathrm{C}$ in increasingly stringent solutions up to $0.1 \times$ SET. When run-on labeled RNA was hybridized, the filters were incubated after washing with RNase A $\left(50 \mu \mathrm{g} / \mathrm{ml}\right.$ in $2 \times \mathrm{SET}$ at $37^{\circ} \mathrm{C}$ for $\left.30 \mathrm{~min}\right)$ to remove single- stranded regions or unhybridized tails. Filters were exposed to Kodak XAR film using intensifying screens. Densitometry was carried out with an Ortec 4310 densitometer, using several film exposures to insure linearity of response.

Samples to be compared by RNA gel blot analysis were loaded in equal amounts $(10 \mu \mathrm{g})$ onto agarose gels; since the mass of RNA is constant during embryogenesis, the relative transcript prevalence per embryo can be compared directly. Minor variations in loading and blot transfer efficiency were assessed by hybridization of the blot to a cDNA (ftpLpG15B6) corresponding to the small subunit of mitochondrial ribosomal RNA, which is constant in amount during embryogenesis. For Northern and dot blots, hybridization signals were proportional to the mass of RNA blotted, indicating sufficient probe excess.

\section{Run-on assay of transcriptional activity}

Nuclei were prepared by a modification of the method of Morris and Marzluff (1983). Embryos washed through CMFSW, were washed with $0.25 \mathrm{M}$ sucrose, $0.1 \mathrm{~mm}$ EDTA, $10 \mathrm{~mm}$ Tris-HCl (pH 8.0). They were then homogenized with 6-10 strokes of a Dounce B pestle in $0.32 \mathrm{M}$ sucrose, $5 \mathrm{mM} \mathrm{MgCl}_{2}, 1 \mathrm{~mm}$ EGTA, 1 $\mathrm{mM}$ dithiothreitol (DTT), $1 \mathrm{~mm}$ spermidine, $0.1 \mathrm{~mm}$ phenylmethylsulfonylfluoride (PMSF), and $10 \mathrm{mM}$ Tris- $\mathrm{HCl}(\mathrm{pH} 8.0)$. This lysate was brought to $1.6 \mathrm{M}$ sucrose and centrifuged at $8000 \mathrm{~g}$ for $10 \mathrm{~min}$. The supernatant was used to prepare RNA for Northern blot analysis. The crude nuclear pellet was resuspended in storage buffer $[25 \%$ glycerol, $1 \mathrm{~mm}$ EGTA, $1 \mathrm{~mm}$ spermidine, $1 \mathrm{mM}$ DTT, $0.1 \mathrm{mM}$ PMSF, $50 \mathrm{~mm}$ Tris- $\mathrm{HCl} / \mathrm{pH}$ $8.0)$ l, to a concentration of approximately $5 \times 10^{9} \mathrm{nuclei} / \mathrm{ml}$. Aliquots of $0.1 \mathrm{ml}$ were either frozen and stored in liquid nitrogen or used immediately for the run-on reaction. All manipulations were carried out quickly at $0-4^{\circ} \mathrm{C}$. RNA chain extension was initiated by the addition of $0.1 \mathrm{ml}$ (an equal volume) of $40 \mathrm{mM} \mathrm{NaCl}, 100 \mathrm{~mm}$ potassium acetate, $2.5 \mathrm{mM} \mathrm{MgCl}_{2}, 0.3 \mathrm{M}$ glycine, $10 \mathrm{~mm}$ Tris- $\mathrm{HCl}(\mathrm{pH} 8.0), 500 \mu \mathrm{M}$ each ATP, GTP, and $\mathrm{CTP}$, and $250 \mu \mathrm{Ci}\left[\alpha^{-32} \mathrm{P}\right] \mathrm{UTP}(\sim 3000 \mathrm{Ci} / \mathrm{mmole}$, Amersham). After incubation at $20^{\circ} \mathrm{C}$ for $20 \mathrm{~min}$, the nuclei were frozen in liquid nitrogen. RNA was isolated from nuclei essentially as described by Groudine et al. (1981). For comparison of samples by hybridization to filters, equal inputs of radioactivity were used; the specific activities of these RNA preparations were similar. Hybridization was quantified by densitometry of autoradiographs and by scintillation counting.

Hybridization of this chain-extended RNA to 15D6 DNA was linearly related to RNA input over a 10-fold range (data not shown). After the standard incubation of $72 \mathrm{hr}$, very little RNA remained capable of hybridization to DNA sequences represented on the first filter, but the RNA remained sufficiently intact to hybridize to other DNA sequences on a second filter. Thus, the filter-bound DNA is in sufficient excess and the hybridization reaction approaches completion, allowing comparison of the fraction of active polymerase bound to a DNA sequence in different preparations of nuclei.

\section{DNA sequencing}

The homologous cDNA clones $15 \mathrm{D} 6$ and $15 \mathrm{C} 8$ were subcloned into Bluescribe and a nested set of deletions produced by Bal31 nuclease digestion. Both DNA strands were sequenced by a dideoxynucleotide chain-termination method.

\section{Acknowledgments}

This research was supported by grants from NSERC and National Institutes of Health (HD-18332) to B.P.B. R.C. received 
an NSERC scholarship. F. Ouellette provided help with the manuscript. William Klein kindly provided Specl and Spec4 (CyIIIa actin) plasmids. The use of trypsin to promote interspecies fertilization was elaborated from methods developed in the Embryology Course of the Marine Biological Laboratory, Woods Hole, by E. Brault, J. Welch, and W. Crain, based on suggestions provided by D. McClay.

\section{References}

Angerer, R.C., E.H. Davidson, and R.J. Britten. 1976. Singlecopy DNA and structural gene sequence relationship among four sea urchin species. Chromosoma 56: 213-226.

Bédard, P.-A. and B.P. Brandhorst. 1983. Patterns of protein synthesis and metabolism during sea urchin embryogenesis. Dev. Biol. 96: 74-83.

- 1986. Cytoplasmic distributions of translatable mRNA species and the regulation of patterns of protein synthesis during sea urchin embryogenesis. Dev. Biol. 115: 261-274.

Blin, N. and D.W. Stafford. 1976. A general method for isolation of high molecular weight DNA from eukaryotes. Nucleic Acids Res. 3: 2303-2308.

Brandhorst, B.P. 1985. The information content of the echinoderm egg. In Developmental biology: A comprehensive synthesis (ed. L. Browder), vol. 1, Oogenesis, pp. 525-576. Plenum, New York.

Brandhorst, B.P. and T. Humphreys. 1972. Stabilities of nuclear and messenger RNA molecules in sea urchin embryos. $I$. Cell. Biol. 53: 474-482.

Brandhorst, B.P., D.P.S. Verma, and D. Fromson. 1979. Polyadenylated and nonpolyadenylated mRNA fractions from sea urchin embryos code for the same abundant proteins. Dev. Biol. 71: 128-141.

Brandhorst, B.P., P.-A. Bédard, F. Tufaro, and R. Conlon. 1986. The persistent role of maternal information during embryogenesis of the sea urchin. In Gametogenesis and the early embryo, pp. 283-303. A.R. Liss, New York.

Cabrera, C.V., J.W. Ellison, J.G. Moore, R.J. Britten, and E.H. Davidson. 1982. Regulation of cytoplasmic mRNA prevalence in sea urchin embryos: Rates of appearance and turnover for specific sequences. J. Mol. Biol. 179: 75-111.

Carpenter, C.D., A.M. Bruskin, P.E. Hardin, M.J. Keast, J. Anstrom, A.L. Tyner, B.P. Brandhorst, and W.H. Klein. 1984. Novel proteins belonging to the troponin $\mathrm{C}$ superfamily are encoded by a set of mRNAs in sea urchin embryos. Cell 36: $663-671$.

Chen, P.S. and F. Baltzer. 1979. Morphology and biochemistry of diploid and androgenetic haploid (merogonic) hybrids. In The sea urchin embryo: Biochemistry and morphogenesis (ed. G. Czihak), pp. 424-472. Springer-Verlag, Berlin.

Church, G.M. and W. Gilbert. 1984. Genomic sequencing. Proc. Natl. Acad. Sci. 81: 1991-1995.

Conlon, R. 1985. M.Sc. thesis, McGill University.

Crain, W.R. and F.D. Bushman. 1983. Transcripts of paternal and maternal actin gene alleles are present in interspecific sea urchin hybrids. Dev. Biol. 100: 190-196.

Davidson, E.H. 1976. Gene activity in early development, 2nd ed. Academic Press, New York.

- 1986. Gene activity in early development, 3rd ed. Academic Press, Orlando.

Fedecka-Bruner, B., M. Anderson, and D. Epel. 1971. Control of enzyme synthesis in early sea urchin development. Aryl sulfatase activity in normal and hybrid embryos. Dev. Biol. 25: 655 .

Galau, G.A., E.A. Lipson, R.J. Britten, and E.H. Davidson. 1977.
Synthesis and turnover of polysome mRNAs in sea urchin embryos. Cell 10: 415-432.

Gross, P.R., L.I. Malkin, and W.A. Moyer. 1964. Templates for the first proteins of embryonic development. Proc. Natl. Acad. Sci. 51: 407-414.

Groudine, M., M. Peretz, and H. Weintraub. 1981. Transcriptional regulation of hemoglobin switching in chicken embryos. Mol. Cell. Biol. 1: 281-288.

Grula, J.W., T.J. Hall, J.A. Hunt, T.D. Giugni, G.J. Graham, E.H. Davidson, and R.J. Britten. 1982. Sea urchin DNA sequence variation and reduced interspecies differences of the less variable DNA sequences. Evolution 36: 665-676.

Hamer, D.H., D.J. Thiele, and J.E. Lemontt. 1985. Function and autoregulation of yeast copperthionein. Science 228: 685690.

Honjo, T. and R.H. Reeder. 1973. Preferential transcription of Xenopus laevis ribosomal RNA in interspecies hybrids between Xenopus laevis and Xenopus mulleri. J. Mol. Biol. 80: $217-228$.

Hörstadius, S. 1939. The mechanics of sea urchin development, studies by operative methods. Biol. Rev. Camb. Philos. Soc. 14: $132-179$.

Humphreys, T. 1971. Measurements of messenger RNA entering polysomes upon fertilization of sea urchin eggs. Dev. Biol. 26: 201-208.

Klein, W.H., S.H. Harding, and B.P. Brandhorst. 1986. Spec proteins: Calcium binding proteins in embryonic ectoderm cells of sea urchins. Methods Enzymol. 139: (in press).

Lee, J.J., F.J. Calzone, R.J. Britten, R.C. Angerer, and E.H. Davidson. 1986. Activation of sea urchin actin genes during embryogenesis: Measurements of transcript accumulation from five different genes in S. purpuratus. I. Mol. Biol. 188: $173-190$.

Lehrach, H., D. Diamond, J.M. Wozney, and H. Boedtker. 1977. RNA molecular weight determinations by gel electrophoresis under denaturing conditions, a critical reexamination. Biochemistry 16: 4743-4750.

Maniatis, T., E.F. Fritsch, and J. Sambrook. 1982. Molecular cloning: A laboratory manual. Cold Spring Harbor Laboratory, Cold Spring Harbor, New York.

March, C.J., B. Mosley, A. Lousen, D.P. Cerretti, G. Braedt, V. Price, S. Gillis, C.S. Henney, S.R. Kronheim, K. Grabstein, P.J. Conlon, T. Hopp, and D. Cosmon. 1985. Cloning, sequence, and expression of two distinct humoral interleukin1 complementary DNAs. Nature 315: 641-647.

Maxson, R.E. and J.C. Egrie. 1980. Expression of maternal and paternal histone genes during early cleavage stages of echinoderm hybrid Strongylocentrotus purpuratus $\times$ Lytechinus pictus. Dev. Biol. 74: 335-342.

McGrath, J. and D. Solter. 1984. Completion of mouse embryogenesis requires both maternal and paternal genomes. Cell 37: $179-183$.

Morris, G.F. and W.F. Marzluff. 1983. A factor in sea urchin eggs inhibits transcription in isolated nuclei by sea urchin RNA polymerase III. Biochemistry 22: 645-653.

Nemer, M., E.C. Travaglini, E. Rondinelli, and J. D'Alonzo. 1984. Developmental regulation, induction, and embryonic tissue specificity of sea urchin metallothionein gene expression. Dev. Biol. 102: 471-482.

Nemer, M., D.G. Wilkinson, E.C. Travaglini, E.J. Sternberg, and T.R. Butt. 1985. Sea urchin metallothionein sequence: Key to an evolutionary diversity. Proc. Natl. Acad. Sci. 82: 4992-4994.

Ozaki, H. 1975. Regulation of isozymes in interspecies sea urchin hybrid embryos. In Izosymes (ed. C.L. Markert), vol. III, pp. 543. Academic Press, New York. 


\section{Conlon et al.}

Posakony, J.W., C.N. Flytzanis, R.J. Britten, and E.H. Davidson. 1983. Interspersed sequence organization and developmental representation of clone poly|A| RNAs from sea urchin eggs. J. Mol. Biol. 167: 361-389.

Reeder, R.H. 1985. Mechanisms of nucleolar dominance in animals and plants. J. Cell. Biol. 101: 2013-2016.

Surani, M.A.H., S.C. Barton, and M.L. Norris. 1986. Nuclear transplantation in the mouse: Heritable differences between parental genomes after activation of the embryonic genome. Cell 45: 127-136.

Tagaki, M. and M. Sasaki. 1975. Preferential inactivation of the paternally derived $\mathrm{X}$ chromosome in the extra embryonic membranes of the mouse. Nature 256: 640-642.

Thiele, D.J., M.J. Walling, and D.H. Hamer. 1986. Mammalian metallothionein is functional in yeast. Science 231: 854856.

Tufaro, F. and B.P. Brandhorst. 1982. Restricted expression of paternal genes in sea urchin interspecies hybrids. Dev. Biol. 92: 209.

Wilkinson, D.G. and M. Nemer. 1987. Metallothionein genes MTa and MTb expressed under distinct quantitative and tissue-specific regulation in sea urchin embryos. Mol. Cell. Biol. 7: 48 . 


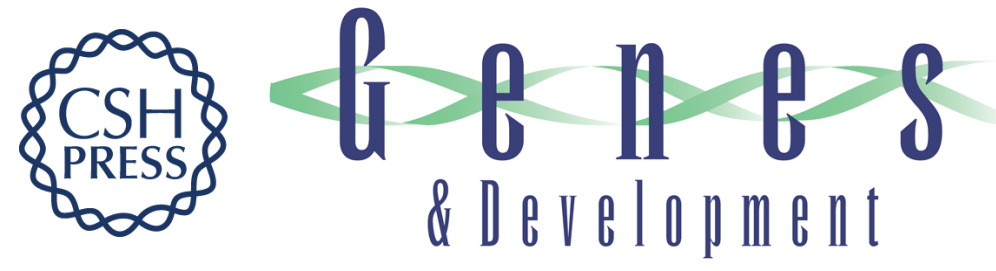

\section{Post-transcriptional restriction of gene expression in sea urchin interspecies hybrid embryos.}

R A Conlon, F Tufaro and B P Brandhorst

Genes Dev. 1987, 1:

Access the most recent version at doi:10.1101/gad.1.4.337

References This article cites 34 articles, 9 of which can be accessed free at: http://genesdev.cshlp.org/content/1/4/337.full.html\#ref-list-1

License

Email Alerting

Service

Receive free email alerts when new articles cite this article - sign up in the box at the top right corner of the article or click here.

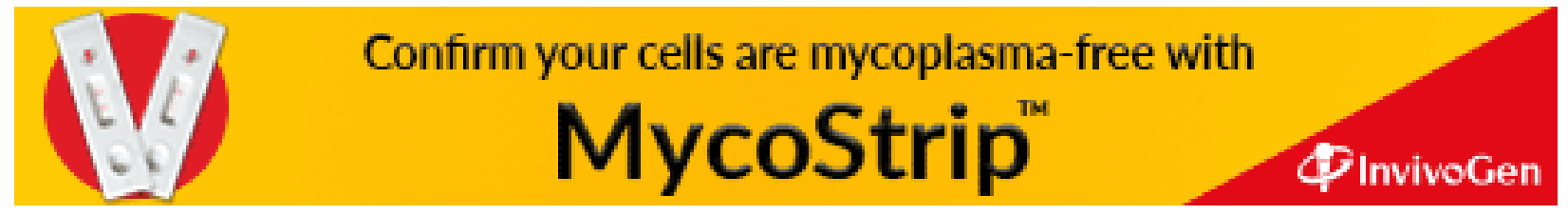

